\title{
Donec non sumus deos temporis: id talis machina nobis
}

\section{non est!..}

(К вопросу о корректности одной общепризнанной фризиками парадигмы)

\section{I. Вступительный раздел}

Серьезная академическая наука гласит, что путешествия во времени возможны лишь в одну сторону, а именно - в будущее. Ведь при возвращении в прошлое мы нарушаем незыблемые фундаментальные законы причинности. И, к слову, как раз из-за этого, хотя бы мельком побывав в грядущем, мы затем уже никогда, по-видимому, не сможем вернуться в свою привычную среду обитания.

Особняком, правда, тут стоит идея, высказанная еще в начале 90-х моим уже покойным другом Вадимом Чернобровом: дескать, путешествовать вполне позволительно в обе стороны, так как речь якобы идет не о посещении гипотетическими хроноплавателями нашего собственного бытия, а только лишь неких параллельных Вселенных. Однако поскольку данную версию невозможно ни подтвердить, ни опровергнуть, то логичней, пожалуй, всё ж таки отнести её к разряду банально-безобидных фантазий, а не к подлинно научной проблематике.

Что же касается общепринятого нынче постулата об однонаправленности стрелы времени, то он пока тоже противоречит, увы, многим нашим обыденным житейским стандартам, базирующимся на практически всюду соблюдаемой атрибутивной симметрии типа «плюс-минус», «больше-меньше», «вперед-назад», «вправо-влево». То есть 
такая ярко выраженная исключительность «Его величества Хроноса» тем самым как бы уже а priori недоступна осознанному человеческому восприятию.

Хотя, впрочем, этот понятийный конфликт легко затушевывается посредством кардинального переосмысления бытующей пространственно-временной парадигмы. Ну и, кроме того, как уже неоднократно отмечалось в предыдущих авторских статьях, подобная обновленная трактовка фрактора времени наверняка помогла 6 разобраться также и с пресловутой «темной энергией», которой на самом-то деле вообще не существует.

\section{II. Под грифом «ретро»}

В начале XX века - и во многом как раз благодаря поразительному энтузиазму и упорству Майкельсона (сумевшего своими сверхточными опытами доказать инвариантность скорости света) - была создана специальная теория относительности. А последовавшие затем воистину бессмертные работы Лоренца, Пуанкаре и Эйнштейна привели к коренной качественной перезагрузке в научной сфрере, но вместе с нею, увы, и к появлению новых нерешенных загадок. То есть, иными словами, с развитием СТО мы стали наконец-то по-настоящему понимать те основополагающие принципы и аксиомы, которыми руководствуется Вселенная. А кроме того, один из весьма полезных практических результатов данной теории заключается как раз в возможности адекватно рассчитать все допустимые пространственно-временные корреляции (в том числе и для стремительно движущегося объекта). И вот тут- 
то уже в умах физиков подспудно вызрела другая пока ещё отчаянная, но вполне достойная внимания творческая идея: а реально ли вообще (т.е. в соответствии с существующими природными законами) ускорить течение времени до таких параметров, чтоб обогнать грядущее? Ну или, скажем, наоборот: можно ли хоть каким-то образом попасть на подобном воображаемом «хронолете» в прошлое?

Как известно, в серии своих теоретических исследований Хендрик Лоренц вывел ряд закономерностей, связанных с преобразованием четырёхмерного пространственновременного континуума. Пусть у нас есть некая система отсчёта $K$, относительно которой движется система $K^{\prime}$, в которой находится наблюдаемый объект. Одно из преобразований Лоренца гласит, что

$$
t=\frac{t^{\prime}+\frac{v}{c^{2}} x^{\prime}}{\sqrt{1-\frac{v^{2}}{c^{2}}}}(1)
$$

где $t$ - момент времени в системе отсчёта $K$ (соответственно, t' - в системе $\left.K^{\prime}\right), x^{\prime}$ - координата наблюдаемого объекта в системе $K^{\prime}$ (считаем её постоянной), v- скорость системы $K^{\prime}$, с - скорость света. Это преобразование связывает между собой моменты времени относительно движущейся системы, и системы, которая покоится. Исходя из того, что скорость тела никогда не превзойдёт скорость света, можно сделать вывод,

что гамма-фактор $\frac{1}{\sqrt{1-\frac{v^{2}}{c^{2}}}} \geq 1$, из чего следует, что для системы K' время будет течь медленнее. 
Путешествуя в прошлое, мы нарушаем причинноследственные связи, и то, что уже произошло, может исчезнуть навсегда: ведь одно событие является причиной другого. И наоборот: если предшествующее никогда не происходило, то и результата не должно быть.

Ярким таким примером является «парадокс убитого дедушки»: если какой-то внук вернётся далеко в прошлое и убьёт своего деда, то его рождение окажется невозможным. Однако если внук не родился, то и деда никто не убивал, так что внук всё-таки родился. В этом-то как раз и заключается логическая суть данного противоречия.

Посмотрим теперь снова на преобразования Лоренца, т.е.

на формулу (1) - и заметим, что гамма-фактор $\frac{1}{\sqrt{1-\frac{v^{2}}{c^{2}}}}$ никогда не станет отрицательным, то есть верным является неравенство $t \geq t^{\prime}$. А отсюда уж прямиком напрашивается вывод, что поскольку следствие не может предшествовать причине, то значит, и путешествие в прошлое невозможно.

Кстати, ровно полвека тому назад (а именно - в 1971 г.) молодым американским физикам Р. Китингу и Дж. Хафеле удалось провести сравнительно простой и дешевый, но давно уже востребованный наукой опыт по проверке справедливости СТО. Для этого они взяли с собой несколько цезиевых хронометров и совершили с ними два авиарейса вокруг земного шара. В результате экспериментально полученные данные по изменению хода времени на борту самолёта (относительно контрольных покоящихся часов) 
полностью совпали с расчётными. Что, таким образом, явилось еще одним убедительным аргументом в пользу корректности преобразований Лоренца.

Казалось бы, всё окончательно расставлено по своим местам и пора уж прекращать любые досужие спекуляции на тему «убитого дедушки». Но не тут-то было. Ибо пресловутая общая теория относительности (так и проигнорированная, кстати, экспертами «нобелевского комитета») допускает здесь, оказывается, возможность каких-то особых червоточин, сквозь которые как будто бы совсем уже и нетрудно проникнуть в прошлое. То есть налицо достаточно весомые предпосылки к ревизии или даже отрицанию основополагающего постулата о всеобщей причинности любых наблюдаемых в природе явлений.

Воспротивиться этому «червоточному» нонсенсу попытались было представители такого элитарноинтеллектуального вида спорта, как бильярд. Допустим рассуждали они - у нас есть воображаемый игровой шар, который катится по некой досконально рассчитанной траектории, попадая в раннюю версию самого же себя; но при этом воздействуя на свою бывшую ипостась (т.е. применительно к шару - координаты, импульс и путь) так, чтобы все эти параметры сохранили в целом прежний свой “modus vivendi". Однако в таком случае мы уже поневоле сталкиваемся тут с другим весьма неприятным парадоксом причинной петлёй (это когда следствие превращается в собственную причину, что приводит в итоге к полному зацикливанию данного процесса). 
Над адекватным истолкованием самых разнообразных бильярдных опций и возможностей более чем достаточно потрудились в свое время нобелевский лауреат Кип Стивен Торн, творец теории суперструн Джозеф Полчински-младший, президент «Американского астрономического общества» Дж. Крейг Уиллер, популярный на Западе писатель-фантаст Роберт Лалл Форвард, но - увы - без какого-то особого успеха. Так что, пожалуй, единственная польза от этих почти напрасных логико-вероятностных мудрствований была в конце концов извлечена лишь прославленным австрочешским кибернетиком Хансом Моравеком для усовершенствования итерационного метода в ЭВМ, а также разработчиками соответствующих компьютерных видеоигр, где сюжет зачастую строится как раз на таких вот «причинно-петлевых» корреляциях.

\section{III. Учите диамат, тов. профессор!}

Отдельно следовало бы здесь остановиться на так называемом «принципе самосогласованности И.Д.Новикова»; тем более что в бытность свою начальником Центра теоретической астрофизики (а позже - замдиректора новосозданного АЦ ФИАН), Игорь Дмитриевич таки и вправду предпринимал всяческие попытки сконструировать некое подобие интертемпоральной капсулы. Причем в отличие от В.А.Черноброва (который параллельно с ним работал над ускорением или задержкой внутренних временных параметров у представителей мелкой биоты и природных минералов) именитый российский профессор на полном 
серьезе собирался-таки встретиться с динозаврами, мамонтами и легендарными библейскими патриархами...

К слову сказать, вот как конкретно формулируется его пресловутая гипотеза: «Разновременные события влияют друг на друга вдоль замкнутой кривой траектории саморегулирующимся циклическим образом. Поэтому единственные решения законов физики, имеющие место в нашем Универсуме, - это те, которые являются глобально самосогласованными». Причем, как легко заметить, у данного постулата есть вполне отчетливое сходство с небезызвестным антропным принципом. Ибо в обоих случаях Вселенная якобы должна сама как-то уж подстраиваться под личные запросы и потребности абстрактного наблюдателя. Или же - в переводе на более доходчивый русский язык - это называется «с больной головы - на здоровую!».

А кроме того, в концепции Новикова любой человеческий индивид волей-неволей уподобляется простому бездушному роботу. Потому как, попав в предшествующую ему эпоху, он не имеет права нарушить некую раз и навсегда установленную пространственно-временную траекторию. Гм... Постойте, товарищ членкор: но ведь с философской точки зрения это является самым настоящим дремучим махрово-мракобесным соскальзыванием с позиций общепринятого ныне в ученом мире релятивистского индетерминизма! Ибо, как всем нам известно, даже и сугубо посюсторонняя человеческая жизнь по своей природе многовекторна: она, в частности, зависит не только от внешней макроструктуры, но и от тонких подспудных 
влияний (в том числе - со стороны звёзд, земной мантии и вселенской ноосферы, не говоря уж о спонтанных виртуально-квантовых флуктуациях на уровне «я»). В представленной же вами трактовке всё это тупо ничтоже сумняшеся проигнорировано!..

Причем, на мой взгляд, главная первопричина вполне очевидных мировоззренческих заблуждений Игоря Дмитриевича кроется в том, что на механико-математическом факультете МГУ (который он закончил еще в 1959 г.) недостаточно внимания уделялось гуманитарным наукам. Ведь, как мы уже прекрасно знаем по своему повседневному опыту, отнюдь не всё то, что постулирует математика, так же легко реализуется и в обыденной жизни. Иначе говоря, практическая вероятность каких-то чересчур уж спекулятивных сценариев или сложных витиеватых комбинаций то ли к сожалению, то ли, быть может, к счастью неумолимо близится к нулю.

Ну а касательно всех прочих «ретро-вояжных» конструктов, то тут дело обстоит, пожалуй, еще хуже, ибо они имеют смысл разве что лишь в заведомо казуальном случае навеки и чётко запечатленной кинохроники, называемой еще по-хрестоматийному «ленточкой Минковского». Которая, в свою очередь, вполне может служить типичным образчиком явного неософистского резонёрства или вообще даже неким бредовым измышлением абстрактного человеческого ума. Причем, по большому счету, то же самое касается и «экзотической» (безбарионной) материи, хотя именно ею так широко (но чаще всего, правда, 
весьма голословно) манипулируют нынче адепты кротовых нор. Ведь она, если уж до конца тут разобраться, представляет собой обыкновенную свежеиспеченную вариацию на тему параллельных миров (ну или, скажем, в альтернативной подаче - какую-то особую «инородную» область воображаемого Мультиверсума).

С другой стороны, хоть нам, судя по всему, таки никогда уже не удастся совершить путешествие в прошлое, но вместе с тем мы имеем реальный шанс лицезреть Вселенную такой, какой она была еще миллионы лет назад, а конкретно - в тех корпускулярно-волновых/(и в частности, реликтовых) потоках, которые прилетают к нам из её бездонных глубин.

А кроме того, смутное опосредованное созерцание прошлого (как, кстати, и грядущего) де-факто всё же на практике вполне осуществимо, но только в общем контексте давящей астрологической зависимости (Иоанн Богослов, Нострадамус, Вангелия Гущерова). И - что самое главное для этого не надо даже никуда перемещаться! Впрочем, более обстоятельно о такой уникальной возможности мы поговорим уже в завершающем разделе данной статьи.

\section{IV. Погасить любопытство-то можно, но назад отступления нет!}

Как мы только что выяснили, согласно преобразованиям Лоренца, время в движущейся системе будет течь медленней, что в целом делает доступными путешествия в будущее. 
Но, оказывается, и тут можно при внимательном подходе обнаружить множество разных двусмысленных тупиков и нестыковок. Представим себе, например, что один из братьев-близнецов отправился в путешествие к далёкой планете на гипотетическом сверхскоростном корабле. И когда он вернётся домой, то другой брат, очевидно, опередит уже его в возрасте. Однако с чего это мы вдруг решили, что постареет именно оставшийся на Земле? Ведь если взять систему отсчёта относительно корабля, то время, вроде бы, должно замедлиться как раз для землянина!

Обоснование же может быть здесь следующим: на пути летящего вдаль корабля есть участки, где он ускоряется или же, наоборот, чуть-чуть притормаживает (для простоты отождествим их с точками, так как они сравнительно малы). То есть в этом случае систему «космический корабль» нельзя уже отнести к инерциальным и для него мировая линия будет искривляться. А вот для земного наблюдателя она останется прямой.

Таким образом, поскольку в пространстве-времени пилотируемый аппарат прошёл больший путь, чем наша родная планета, но в итоге ими было совершено одинаковое перемещение, то для движущегося корабля прошло больше времени. И следовательно - именно он совершил путешествие в будущее.

Наглядным доказательством замедления времени служат мюоны, время жизни которых около 2,19 мк; так что, даже обладая громадными космическими скоростями, они не должны бы, по идее, преодолевать значительных расстояний. 
Однако в силу релятивистских эффектов промежуток времени до распада в неподвижной системе

$$
\Delta t=t_{2}-t_{1}=\frac{\Delta t^{\prime}}{\sqrt{1-\frac{v^{2}}{c^{2}}}}
$$

будет гораздо длиннее, ведь скорость мюонов близка к световой. И Іэто как раз легко может объяснить тот общеизвестный факт, что мюонам удаётся-таки долетать до нас из самых, казалось бы, отдаленных глубин мироздания.

Что же касается еще одного парадокса (носящего, впрочем, уже не математический, а сугубо житейский характер), то суть его такова: человек или робот, который отправится на сверхсветовом корабле в будущее, никогда уже после этого не сможет вернуться назад и даже передать оттуда какую-либо информацию. Увы!.

\section{V. О всех тайнах и тонкостях пророческого восприятия}

Однако, как уже не раз отмечалось, поразительная способность отдельных земных уникумов к предвидению вполне может быть напрямую и не связана со странствиями по шкале времени. Дело ведь в том, что провидцы созерцают не саму грядущую перспективу, а лишь как-то сопряженное с ней астральное расширение (даже если заимствуют при этом всю искомую информацию от небесных контагентов). В пользу такой явно напрашивающейся гипотезы свидетельствуют и многочисленные случаи из жизни близнецов (которые, развиваясь из единой материнской яйцеклетки, имеют, соответственно, и общий астрал, вследствие чего подвергаются затем и почти одинаковым 
превратностям судьбы). А отсюда, в свою очередь, вытекает, что именно данный метафизический вектор (или, если угодно, теософская оболочка) оказывает наибольшее воздействие на подсознательные поступки человека.

Кстати, подробный всесторонний анализ накопленных наукой фактов свидетельствует, что для обоснования прекогнитивной методики реально подходят только две версии. Всё же остальное представляется здесь либо откровенно притянутым за уши, либо уж, по крайней мере, глубоко сомнительным.

Итак, вот они вкратце:

1) Вычисление нашего будущего некими высшими контагентами - с последующей передачей информации на Землю через избранных медиаторов наподобие Ванги или Нострадамуса. Поскольку оно производится лишь по основному детерминантному вектору - следовательно, носит тут, скорее,_вероятностный, а не утвердительный характер. Причем этот вектор может быть даже и астральным, но при любом раскладе такие сложные многозначные калькуляции доступны только внеземным сущностям (ну или, например, космической ноосфере в целом), тогда как наши доморощенные астрологи могут разве что получить от них какие-то уже готовые сведения.

2) Программирование отдельных якобы «предугаданных» событий. Этот пункт, если и актуален - то, пожалуй, лишь в сочетании с первым. Общий смысл его заключается в следующем: для поддержания реноме избранного провидца или гадалки, как, впрочем, и с целью запугивания землян, 
пранофиты сами всячески способствуют осуществлению ранее предсказанного действия в нужный момент времени (в том числе - через посредство НЛОнавтов, спи-спаев и т.п.).

Что же касается «прямого видения»грядущих событий, то в свете бытующей ныне парадигмы (когда за причиной обязательно должно идти следствие) такой вульгарноидеалистический софизм попросту не выдерживает критики. И наоборот: если, допустим, кому-нибудь удастся вдруг подтвердить реальное существование «ленточки времени» то тогда уж, боюсь, придется волей-неволей выбрасывать на свалку все прежние достижения мировой научной мысли. Кстати говоря, в чем-то схожая ситуация обстоит и с «параллельными универсумами» (т.е. вроде бы всё предсказываемое где-то таки сбывается, однако не обязательно у нас): это еще один образчик типичного пустопорожнего разглагольствования, которое ни к чему толком не ведет.

Так что при обосновании удачных (а главное - строго засвидетельствованных) пророческих случаев чаще всего необходимо учитывать оба фактора: и предваряющий, и программирующий. Но всё же первый из них, само собой разумеется, намного важней (сугубо хотя бы даже этиологически). В свою очередь, среди вторичных (программирующих) рычагов влияния можно здесь выделить следующие:

а) исключительная спорадическая одаренность данной конкретной особи сильным астралом (что, в общем-то, должно как-то проявиться уже с ранних лет); 
б) некая личная заинтересованность со стороны ангела (контагента);

в) полифакторная предикция (скажем, относительно А.С.Пушкина - несколько альтернативных «белых всадников на белом коне»).

И хотя последняя из версий представляется тут несколько надуманной (да и, тем более, в неё, например, не очень-то вписывается изрядно нашумевшая история с казненным декабристом Муравьевым-Апостолом), но всё ж таки право на концептуальное обсуждение она тоже имеет.

\section{VI. Краткое итоговое резюме}

Какие же полезные для науки выводы можно отсюда сделать?

1. Странствия в предшествующие нам эры и эпохи невозможны ни сквозь пресловутые «червоточины», ни с помощью каких-либо иных ухищрений. Да и сам принцип Новикова применим, пожалуй, лишь в неком факультативном смысле, ибо вероятность того, что робот или живое существо осилят этот нелегкий трансцендентный лабиринт (а особенно с учетом всех задействованных тут факторов:

энергетического, технологического, экономического, психосоматического и др.) попросту близка к нулю. Различные же умозрительные спекуляции с бильярдными шарами вообще не выдерживают здесь критики из-за априорной ограниченности такого подхода: как будто ничего больше, кроме самого запускаемого в туннель шара, в реальной 
жизни (т.е. за пределами видимых нами расчётных траекторий) быть не может.

2. Вследствие этого упомянутая уже ранее (см. вступление к данной статье) смелая авторская догадка о божественной природе времени приобретает еще одну/ довольно-таки весомую порцию позитивных бонусов.

3. В отличие от надуманных и абсолютно бредовых ретровояжей, путешествия в будущее вполне возможны; но только если перемещаться с невообразимо огромными околосветовыми скоростями.

4. Множество измышлений человеческого разума отнюдь не эквивалентно совокупности объектов так называемого горизонта Коши. Хотя, понятное дело, речь тут идет не о скудном интеллектуальном багаже какого-то изолированного дикаря, имбецила или преступника-рецидивиста, а именно об условно обобщенном духовном мире всех земных обитателей. В частности, при любых раскладах их ординал будет заведомо выше, т.е. мощнее, чем у аналогичного множества структурных элементов наблюдаемого нами космоса. А значит, всуе выдумать или «высосать из пальца» можно практически всё что угодно. Ведь никто за это ни в тюрьму, ни в «психушку» не посадит и не расстреляет; а Вселенная, между тем, спокойнёхонько будет развиваться дальше своим чередом и ее законы от наших буйных фантазий ни на йоту не изменятся.

Так что пока стрела времени целенаправленно и безудержно несёт нас только в одну сторону - вперёд; и в 
данном контексте совершенно как раз уже не важно, относительно чего...

Эмир Э.Ашиурский /2. Киев/ 